Article

\title{
Microstructure, Texture Evolution and Magnetic Properties of Fe-6.5 wt. \% Si and Fe-6.5 wt. \% Si-0.5 wt. \% Cu Alloys during Rolling and Annealing Treatment
}

\author{
Zhaoyang Cheng, Jing Liu *, Jiachen Zhu, Zhidong Xiang, Juan Jia and Yunjie Bi \\ The State Key Laboratory of Refractories and Metallurgy, Wuhan University of Science and Technology, \\ Wuhan 430081, China; chengzhaoyang@wust.edu.cn (Z.C.); zjc_wust@163.com (J.Z.); \\ zhidongxiang@hotmail.com (Z.X.); queenyjj@hotmail.com (J.J.); yunjiebi@gmail.com (Y.B.) \\ * Correspondence: liujing@wust.edu.cn; Tel.: +86-27-6886-2497
}

Received: 15 November 2017; Accepted: 13 February 2018; Published: 22 February 2018

\begin{abstract}
Sheets of Fe-6.5 wt. \% Si and Fe- 6.5 wt. \% Si-0.5 wt. \% Cu with the thickness of $0.3 \mathrm{~mm}$ have been produced by hot and warm rolling. The microstructure, texture evolution and magnetic properties of the two alloys were investigated. It was found that the addition of $0.5 \mathrm{wt} . \% \mathrm{Cu}$ promoted the formation of shear bands during warm rolling, and enhanced the $\{110\}<001>$ texture at surface layer and $\{111\}<112>$ texture in the middle layer. After annealing treatment, a strong $\eta$ fiber texture with a peak at $\{110\}<001>$ was formed in the Fe- $6.5 \mathrm{wt}$. \% Si-0.5 wt. \% Cu sample, while the Fe-6.5 wt. \% Si sample was characterized by complex $\gamma, \eta$ and $\lambda$ fibers. The formation of dominating $\eta$ fiber in the annealed Fe- $6.5 \mathrm{wt}$. \% Si-0.5 wt. \% Cu sample is attributed to the shear bands formed in $\{111\}<112>$ oriented grains. These shear bands in $\{111\}<112>$ oriented grains acted as the nucleation sites of $\eta$ oriented grains and promoted the growth of Goss oriented grains. The presence of strong $\eta$ fiber with a peak at Goss in Fe-6.5 wt. \% Si-0.5 wt. \% Cu sample was the cause for the higher magnetic induction observed for this sample than for the Fe- $6.5 \mathrm{wt}$. \% Si sample.
\end{abstract}

Keywords: Fe-6.5 wt. \% Si alloy; alloying; microstructure; texture evolution; magnetic properties

\section{Introduction}

Fe-6.5 wt. \% Si alloy is regarded as an ideal material for energy efficient design and miniaturization of a diverse range of electrical devices because of its high electrical resistivity, high permeability and near zero magnetostriction [1,2]. Fe-6.5 wt. \% Si alloy will meet the demands for energy loss reduction, improved efficiency and low noise during the process of electromagnetic transition [3]. However, it is almost impossible to cold-roll Fe-6.5 wt. \% Si alloy into thin sheets for practical applications due to its near zero ductility. The brittleness of Fe- $6.5 \mathrm{wt}$. \% Si alloy at room temperature is caused mainly by the formation of the ordered phases such as $\mathrm{B} 2$ and $\mathrm{D}_{3}$ in the microstructure [4,5]. In fact, commercial scale production of Fe- $6.5 \mathrm{wt}$. \% Si alloy sheets has only been successfully developed by JFE Steel Corporation (Tokyo, Japan) through a chemical vapor deposition (CVD) process [6]. However, the magnetic induction at $800 \mathrm{~A} / \mathrm{m}\left(\mathrm{B}_{8}\right)$ of the sheets with a thickness of $0.3 \mathrm{~mm}$ produced by CVD is about $1.27 \mathrm{~T}$, which is much lower than the theoretical value of $1.8 \mathrm{~T}[7,8]$. Therefore, the magnetic induction of Fe-6.5 wt. \% Si alloy may potentially be improved by further optimizing its texture.

Ros-Yañez et al. [9] described the texture evolution in sheet steel. The texture after hot-rolling was composed of cube $(\{001\}<100>), \gamma(\{111\}$ parallel to the rolling direction) and Goss $(\{011\}<100>)$ components, which evolved to that consisting of strong $\gamma$ and $\lambda(<001>$ parallel to the normal direction) fibers after cold rolling, and finally to the one comprising $\gamma$ fiber with a peak at $\{111\}<110>$ after recrystallization. The recrystallization texture will depend on the heterogeneities in the texture after 
cold rolling. It is desirable to enhance the $\eta$ fiber $(<001>$ parallel to the rolling direction (RD)), and to suppress $\gamma$ fiber $(<001>$ not in the rolling direction). The $\eta$ and $\gamma$ recrystallized grains tend to nucleate mainly in shear bands and grain boundaries, respectively [10-12]. To improve the magnetic induction of Fe- 6.5 wt. \% Si sheets, many efforts have been focused on the formation of $\eta$ fiber. For instance, Liu et al. [13] studied the development of strong $\eta$ primary recrystallization texture in a $0.50 \mathrm{~mm}$ Fe-6.5 wt. \% Si sheet produced by hot and cold rolling; Fang et al. [14] reported a recrystallization texture with a similar intensity of $\eta$ and $\gamma$ fibers in rolled $0.30 \mathrm{~mm}$ thick Fe- $6.5 \mathrm{wt}$. \% Si sheets by cold rolling; and Yao et al. [15] obtained $\eta$ fiber dominated recrystallization texture after high-temperature annealing $\left(950-1150{ }^{\circ} \mathrm{C}\right)$ of a cold-rolled Fe- $6.5 \mathrm{wt}$. \% Si sheets of $0.2 \mathrm{~mm}$ thickness.

Our previous study [16] indicated that the addition of $0.5 \mathrm{wt} . \% \mathrm{Cu}$ could increase the ductility of Fe- $6.5 \mathrm{wt}$. \% Si alloy at intermediate temperature $\left(550{ }^{\circ} \mathrm{C}\right)$, as well as improving the magnetic properties after annealing at $1150{ }^{\circ} \mathrm{C}$ for $1 \mathrm{~h}$. Nevertheless, there have been no studies on the detailed effect of $\mathrm{Cu}$ addition on the microstructure and texture evolution for the Fe- $6.5 \mathrm{wt}$. \% Si alloy, although Bian et al. [17] indicated that a suitable amount of $\mathrm{Cu}$ addition could improve the recrystallization textures of non-oriented silicon steel by inhibiting the $\{111\}$ component and promoting the Goss component. Thus, the focus of this paper is on the evolution of the microstructure and texture of Fe-6.5 wt. \% Si and Fe-6.5 wt. \% Si-0.5 wt. \% Cu alloys during rolling and annealing processes.

\section{Experimental Procedures}

Two Fe- 6.5 wt. \% Si alloys, one without $\mathrm{Cu}$ and one with $0.5 \mathrm{wt}$ \% $\mathrm{Cu}$ addition (labeled as $0 \mathrm{Cu}$ and $0.5 \mathrm{Cu}$, respectively), were prepared by melting of iron ( $99.5 \mathrm{wt}$. \%), silicon ( $99.5 \mathrm{wt}$. \%) and copper (99.9 wt. \%) in a vacuum induction furnace. The ingots were forged into slabs of about $20-30 \mathrm{~mm}$ thickness at $1100{ }^{\circ} \mathrm{C}$, and then hot rolled to $0.8-1.0 \mathrm{~mm}$ at about $1000{ }^{\circ} \mathrm{C}$. The hot-rolled sheets were further warm rolled to $0.3 \mathrm{~mm}$ at approximately $650{ }^{\circ} \mathrm{C}$, and finally annealed at $900{ }^{\circ} \mathrm{C}$ for different times under a nitrogen-hydrogen $\left(\mathrm{N}_{2}+50 \% \mathrm{H}_{2}\right)$ atmosphere.

Optical microscopy (OM) (ZEISS, Jena, Germany) was used to observe the microstructure of samples. Textures of the warm-rolled sheets were quantitatively measured for the three incomplete pole figures $\{110\},\{200\}$ and $\{112\}$ by X-ray diffraction (XRD, $\mathrm{Mo}_{\mathrm{k} \alpha 1}$ radiation, D/MAX-2500PC) (Bruker, Karlsruhe, Germany). The orientation distribution functions (ODFs) were then calculated from the pole figures by series expansion method $\left(I_{\max }=22\right)$. The textures of the warm-rolled sheets were measured at the surface and in the middle layer, and the results were presented in the form of ODFs in the $\varphi_{2}=45^{\circ}$ section. The formation of the recrystallization texture was analyzed by electron backscattered diffraction (EBSD) (Oxford Instruments, Oxford, UK, HKL Channel 5 EBSD equipped on the Nova 400 Nano field emission scanning electron microscope) (FEI, Hillsboro, OR, USA) operated at an accelerating voltage of $30 \mathrm{kV}$ with a step of $0.6 \mu \mathrm{m}$. The microstructure and texture measurements were made on the longitudinal section defined by rolling direction (RD) and normal direction (ND). Moreover, the magnetic induction at $800 \mathrm{~A} / \mathrm{m}\left(\mathrm{B}_{8}\right)$ and $5000 \mathrm{~A} / \mathrm{m}\left(\mathrm{B}_{50}\right)$ of the sheets were measured by an AC/DC magnetic measuring instrument (MPG-100D) (Brockhaus, Lüdenscheid, Germany) with a sample size of $300 \mathrm{~mm} \times 30 \mathrm{~mm} \times 0.3 \mathrm{~mm}$; the length of the sample is in the rolling direction.

\section{Results}

The microstructures were characterized for both the $0 \mathrm{Cu}$ and $0.5 \mathrm{Cu}$ warm-rolled samples with deformed grains and some in-grain shear bands (Figure 1). However, many more shear bands were present in $0.5 \mathrm{Cu}$ sample than in $0 \mathrm{Cu}$ sample (Figure 1). Figure 2 shows the textures of $0 \mathrm{Cu}$ and $0.5 \mathrm{Cu}$ warm-rolled sheets. Here, $L=0$ and 0.5 represent the surface and middle thickness of the sample, respectively. The warm-rolled texture exhibited a gradient along the thickness in both samples. The dominated texture at the surface of the $0 \mathrm{Cu}$ sample was $\{001\}<110>$ with an intensity level of 2.5 , and $\{110\}<001>$ with an intensity level of 2.1. The texture at the middle thickness of the $0 \mathrm{Cu}$ sample was dominated by $\gamma$ fiber with an intensity level of 3.6 and $\{001\}<110>$ component with an intensity level of 2.9. As shown in Figure 2b, the 0.5Cu sample was much more textured than 0Cu sample. 
For the $0.5 \mathrm{Cu}$ sample, the texture in surface mainly consisted of Goss component with an intensity level of 6.9 , while the main texture in middle thickness was $\gamma$ fiber and dominated by $\{111\}<112>$ component with an intensity level of 6.2 . Thus, the addition of $0.5 \mathrm{wt}$. $\% \mathrm{Cu}$ promoted the formation of shear bands during warm rolling, and strengthened the Goss component at surface layer and the $\{111\}<112>$ component at the middle thickness of the warm-rolled sheets.
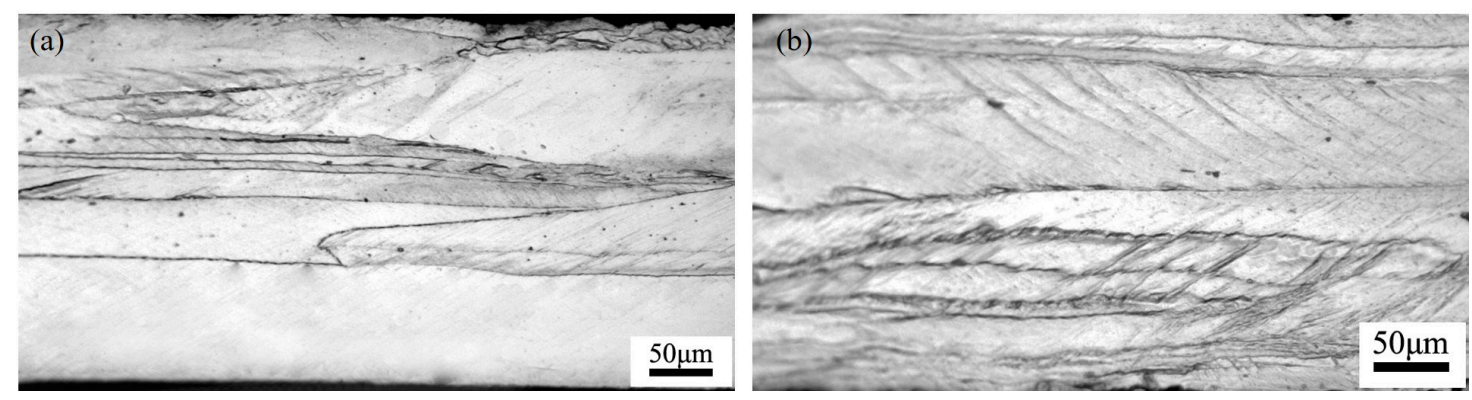

Figure 1. Microstructure of warm-rolled sheets: (a) $0 \mathrm{Cu}$; and (b) $0.5 \mathrm{Cu}$.

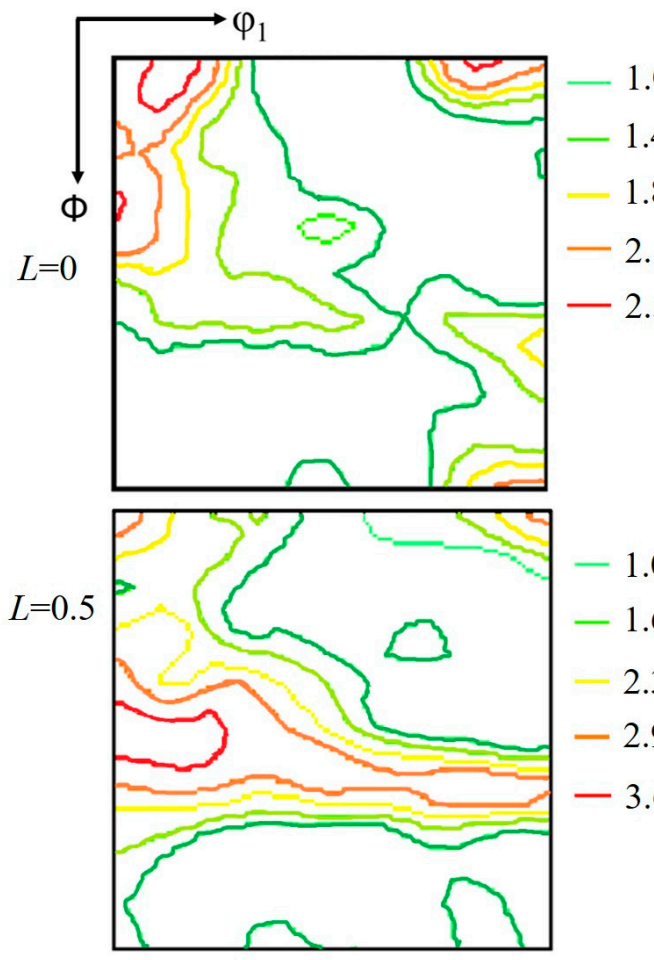

(a)

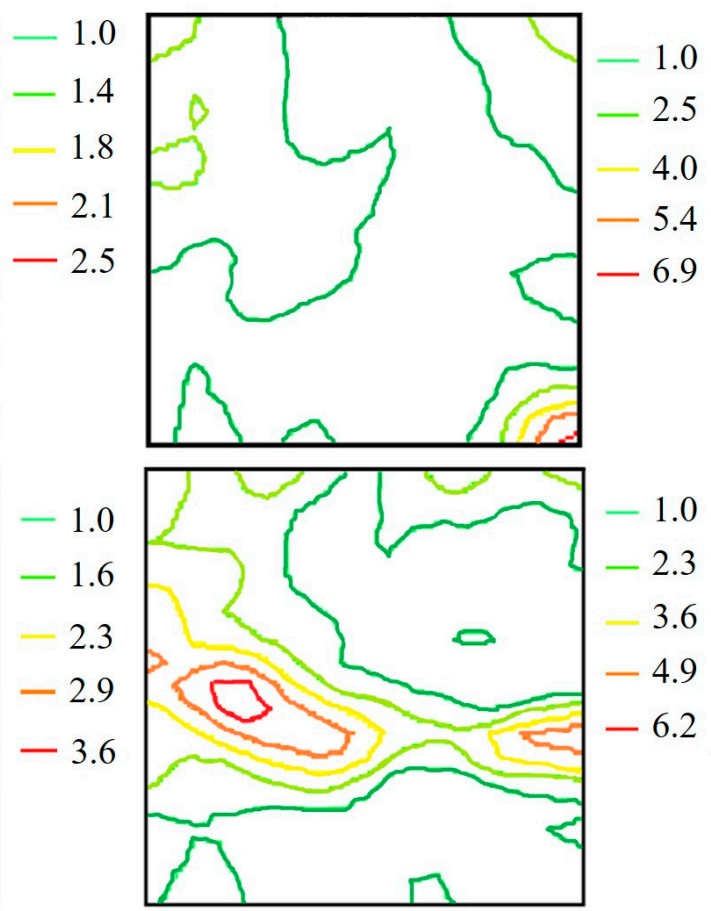

(b)

Figure 2. Constant $\varphi_{2}=45^{\circ}$ section of orientation distribution functions (ODFs) at surface $(L=0)$ and middle layer $(L=0.5)$ in warm rolled sheets: (a) $0 \mathrm{Cu}$; and (b) $0.5 \mathrm{Cu}$.

Figure 3 shows the constant $\varphi_{2}=0^{\circ}$ and $\varphi_{2}=45^{\circ}$ sections of ODFs of the $0 \mathrm{Cu}$ and $0.5 \mathrm{Cu}$ sheets after annealing at $900{ }^{\circ} \mathrm{C}$ for $10 \mathrm{~min}$. The $0 \mathrm{Cu}$ sample exhibited mainly $\gamma$ and $\eta$ fibers, while the $0.5 \mathrm{Cu}$ sample was dominated by $\eta$ fiber (especially Goss). Quantitative analysis of the orientation densities along $\gamma$ fiber $\left(\Phi=55^{\circ}\right.$ and $\left.\varphi_{2}=45^{\circ}\right), \eta$ fiber $\left(\varphi_{1}=0^{\circ}\right.$ and $\left.\varphi_{2}=0^{\circ}\right)$ and $\lambda$ fiber $\left(\Phi=0^{\circ}\right.$ and $\left.\varphi_{2}=45^{\circ}\right)$ showed that the $0 \mathrm{Cu}$ sample was characterized by $\gamma$ fiber with a strong $\{111\}<112>$ component, weak $\eta$ fiber with Goss component, and weak $\lambda$ fiber with $\{001\}<410>$ and $\{001\}<310>$ components (Figure 4 ). By contrast, the texture in the $0.5 \mathrm{Cu}$ sample was dominated by $\eta$ fiber with a strong peak at Goss; the orientation intensity of $\gamma$ and $\lambda$ fibers were extremely weak. 


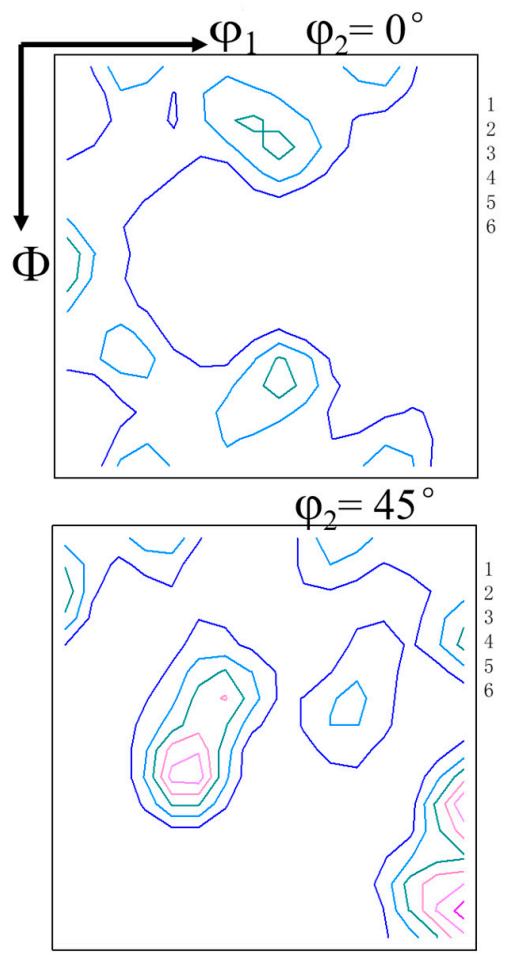

(a)

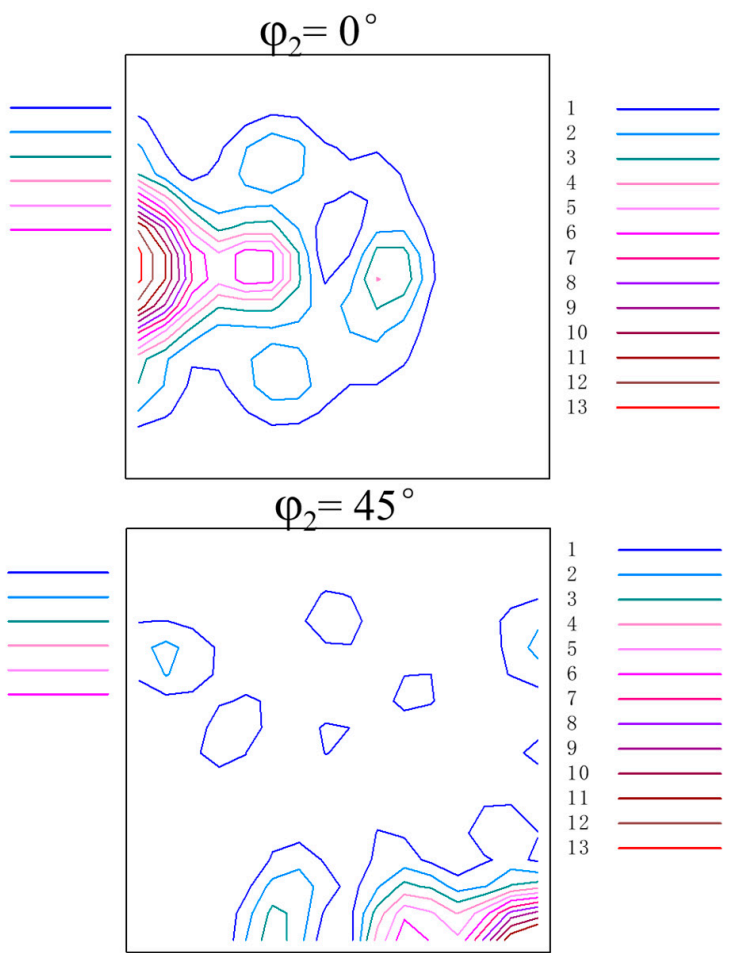

(b)

Figure 3. Constant $\varphi_{2}=0^{\circ}$ and $\varphi_{2}=45^{\circ}$ sections in the sheets annealed at $900{ }^{\circ} \mathrm{C}$ for $10 \mathrm{~min}$ : (a) $0 \mathrm{Cu}$; and $(\mathbf{b}) 0.5 \mathrm{Cu}$.

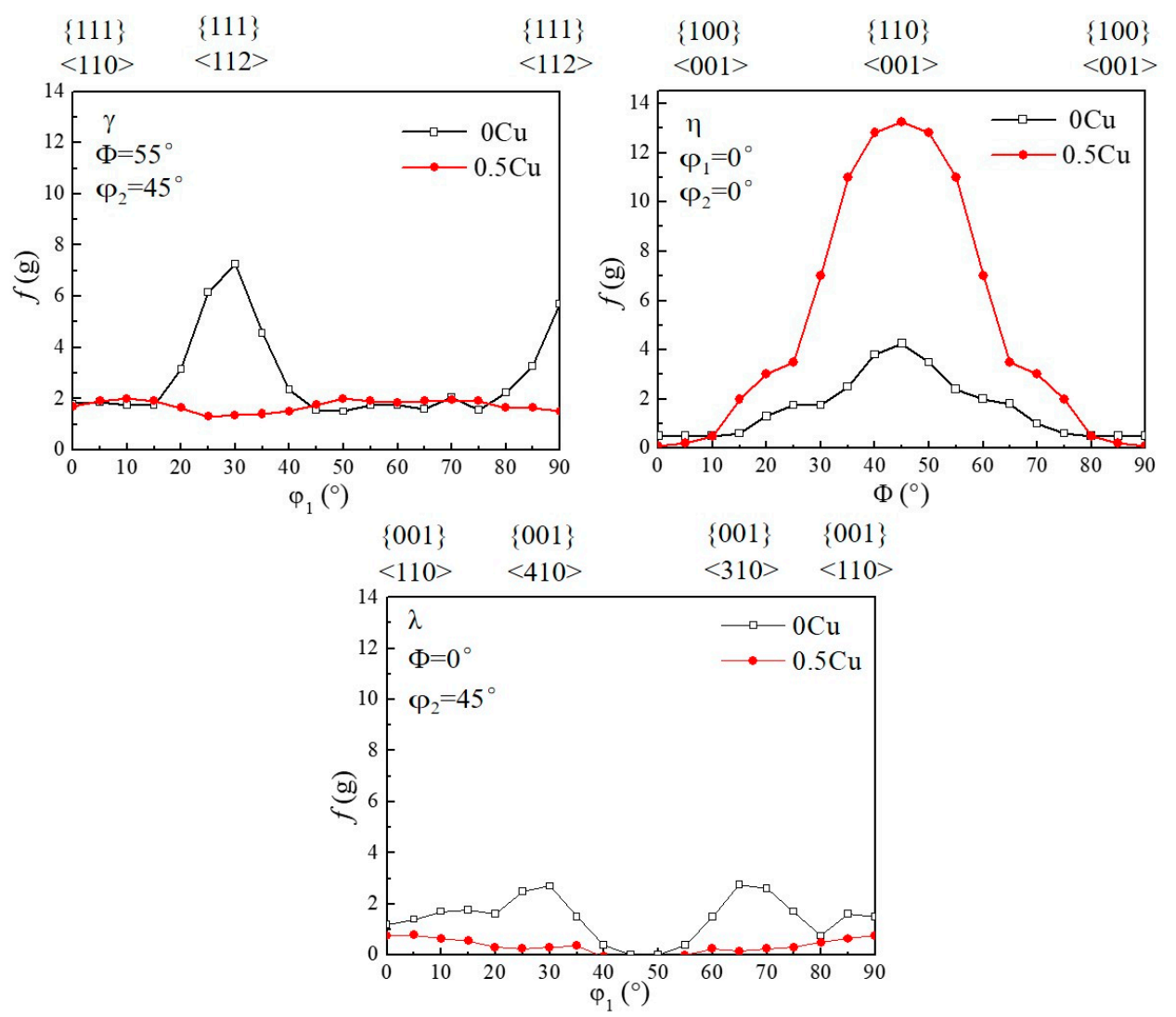

Figure 4. The orientation densities along $\gamma, \eta$ and $\lambda$ fibers of the sheets annealed at $900{ }^{\circ} \mathrm{C}$ for $10 \mathrm{~min}$. 
Table 1 summarizes the magnetic induction of the $0.3 \mathrm{~mm}$ thickness sheets annealed at $900{ }^{\circ} \mathrm{C}$ for $10 \mathrm{~min}$. The $\mathrm{B}_{8}$ and $\mathrm{B}_{50}$ values are higher for the $0.5 \mathrm{Cu}$ sample (1.37 $\mathrm{T}$ and $1.62 \mathrm{~T}$, respectively) than for the $0 \mathrm{Cu}$ sample (1.25 $\mathrm{T}$ and $1.47 \mathrm{~T}$, respectively).

Table 1. The magnetic properties of the sheets ( $0.3 \mathrm{~mm}$ thickness) annealed at $900{ }^{\circ} \mathrm{C}$ for $10 \mathrm{~min}$.

\begin{tabular}{ccc}
\hline Samples & $\mathbf{B}_{8} / \mathbf{T}$ & $\mathbf{B}_{50} / \mathbf{T}$ \\
\hline $0 \mathrm{Cu}$ & 1.25 & 1.47 \\
$0.5 \mathrm{Cu}$ & 1.37 & 1.62 \\
\hline
\end{tabular}

\section{Discussion}

\subsection{Effect of $\mathrm{Cu}$ on the Formation of Shear Bands}

According to the microstructural result of the warm-rolled sheets, the shear band density was indeed higher in the $0.5 \mathrm{Cu}$ sample than in the $0 \mathrm{Cu}$ sample. It has been shown that the formation of shear bands can be influenced by rolling temperature, strain rate sensitivity and microstructure of the alloys [18-21]. The population of shear bands decreases as the rolling temperature increases. At warm rolling temperatures, the strain rate sensitivity is significantly increased, suppressing inhomogeneous plastic flow and hence shear band formation. A higher value of strain-rate sensitivity $(\mathrm{m})$ means that a higher stress is necessary to obtain the same strain. A low strain rate sensitivity will enhance the formation of shear bands and, conversely, a high strain rate sensitivity can suppress their formation within the grains.

Previous study [16] indicated that the addition of $0.5 \mathrm{wt} . \% \mathrm{Cu}$ could improve the ductility of Fe-6.5 wt. \% Si alloy by suppressing the formation of ordered phases in the alloy, and the strain rate sensitivity of the $0.5 \mathrm{Cu}$ sample is lower than that for 0Cu sample. Toroghinejad et al. [18] indicated that a material must contain strong $\{111\}$ and weak $\{001\}$ components to have good formability. The texture measurements of the warm-rolled sheets show that the intensity of the $\gamma$ fiber texture in $0.5 \mathrm{Cu}$ sample is much higher than in the 0Cu sample, and there are some $\alpha$ and $\{001\}$ textures in $0 \mathrm{Cu}$ sample. Therefore, the texture measurement results are consistent with the ductility results. Therefore, a larger number of shear bands will be formed in the $0.5 \mathrm{Cu}$ sample than in the $0 \mathrm{Cu}$ sample according to the formation mechanism of shear bands. As the rolling temperature of the $0 \mathrm{Cu}$ sample and $0.5 \mathrm{Cu}$ sample is the same in this study, lower strain rate sensitivity and better ductility will induce a larger number of shear bands for the $0.5 \mathrm{Cu}$ sample.

Quadir et al. [10] found that the in-grain shear bands have a grain orientation dependency, i.e., such shear bands are present in $\gamma$ grains and almost absent in $\alpha$ grains. According to the texture results in this study, the texture of the $0 \mathrm{Cu}$ sample was dominated by $\gamma$ fiber and $\alpha$ fiber, while the main texture for the $0.5 \mathrm{Cu}$ sample consisted of mainly Goss (the surface) and $\gamma$ fiber (the middle layer), and also the latter sample was more textured than the former sample. Thus, a larger number of shear bands would be expected in the $0.5 \mathrm{Cu}$ sample than in the $0 \mathrm{Cu}$ sample.

\subsection{Effect of Shear Bands on the Nucleation and Growth of $\eta$ Fiber}

It is known that magnetization is hardest in the $<111>$ direction but easiest in the $<001>$ direction of iron crystals [22-24]. Thus, the $\eta$ fiber $(<001>$ parallel to the rolling direction) and the $\lambda$ fiber $(<001>$ parallel to the normal direction) are beneficial for magnetic induction, while the $\gamma$ fiber $(<111>$ parallel to the normal direction) is the least favorable for magnetic induction. As the dominating texture after recrystallization was $\gamma$ and $\eta$ fibers in the $0 \mathrm{Cu}$ sample, and only $\eta$ fiber in the $0.5 \mathrm{Cu}$ sample, the magnetic induction was higher for the $0.5 \mathrm{Cu}$ sample than for the 0Cu sample.

To further analyze the texture evolution during recrystallization, the orientation image maps of the partially recrystallized samples were obtained from EBSD measurements (Figure 5). After annealing at $900{ }^{\circ} \mathrm{C}$ for $30 \mathrm{~s}$, the nucleation sites in the $0 \mathrm{Cu}$ sample were mainly at the boundaries of the 
deformed grains (indicated by circle in Figure 5a), but the recrystallized grains were too coarse to allow identification of the nucleation site in the $0.5 \mathrm{Cu}$ sample (Figure 5b). To identify the nucleation site of the $0.5 \mathrm{Cu}$ sample, its orientation image map was measured after annealing at $900{ }^{\circ} \mathrm{C}$ for only $15 \mathrm{~s}$. In addition to nucleation at grain boundaries, the in-grain shear bands with $\{111\}<112>$ orientation also acted as nucleation sites (highlighted by arrowed lines in Figure $5 c$ ). The grains nucleated at the shear bands grew more quickly than those nucleated at the grain boundaries (Figure 5b,c). Figure 6 summarizes the proportion of $\gamma, \eta$ and $\lambda$ oriented grains in all recrystallized grains observed in Figure $5 \mathrm{a}, \mathrm{b}$. In the $0 \mathrm{Cu}$ sample, the proportion of $\gamma$ oriented grains was evidently the highest, which was followed by that of the $\lambda$ oriented grains (with an area fraction of $27 \%$ and $15 \%$, respectively). The area fraction of $\eta$ oriented grains was less than $5 \%$. For the $0.5 \mathrm{Cu}$ sample, the recrystallized grains were dominated by $\eta$ oriented grains with an area fraction of $25 \%$, whereas the area fractions of the $\gamma$ and $\lambda$ oriented grains were only $8 \%$ and $6 \%$, respectively.
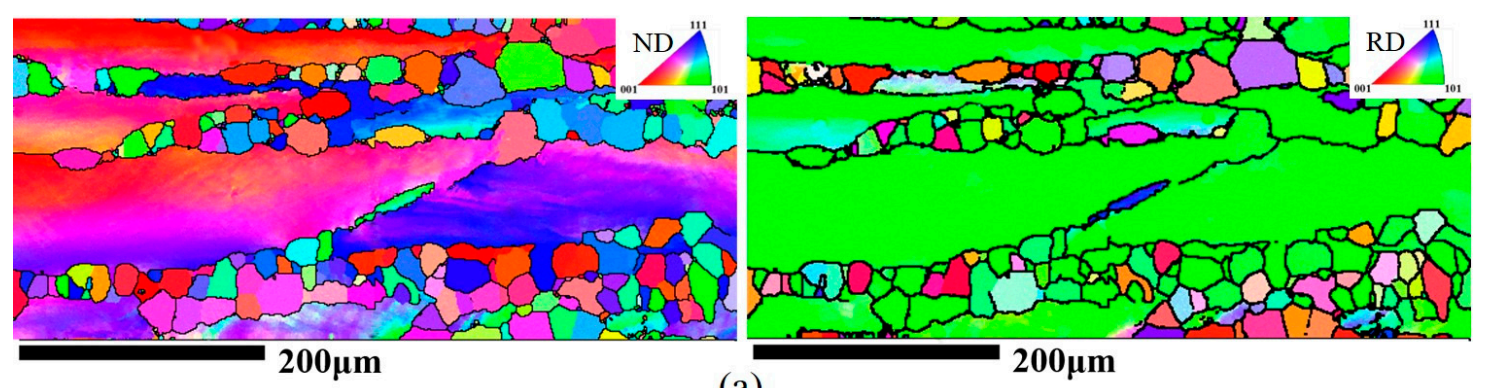

(a)
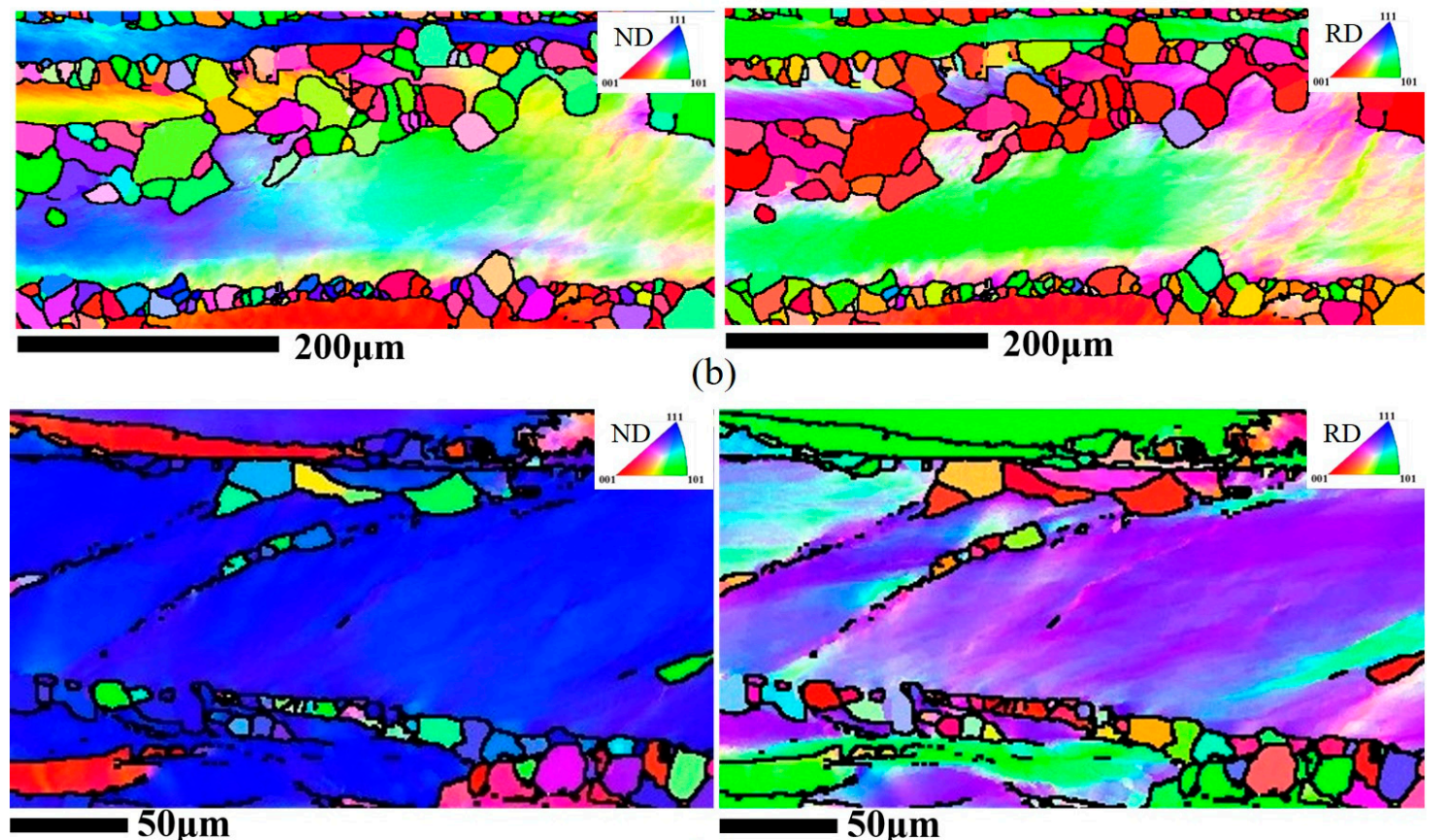

(c)

Figure 5. Orientation image map of partially recrystallized samples: (a) $0 \mathrm{Cu}, 900{ }^{\circ} \mathrm{C} \times 30 \mathrm{~s}$; (b) $0.5 \mathrm{Cu}$, $900{ }^{\circ} \mathrm{C} \times 30 \mathrm{~s}$; and (c) $0.5 \mathrm{Cu}, 900{ }^{\circ} \mathrm{C} \times 15 \mathrm{~s}$. The left images are of the normal direction (ND), while the right images are of the rolling direction (RD).

The boundaries of deformed grains and in-grain shear bands will be the nucleation sites of recrystallization, but the $\eta$ orientation grains will nucleate mainly at the shear bands during recrystallization $[25,26]$. The schematic diagram in Figure 7 illustrates the recrystallization nucleation of the warm-rolled sheets during annealing processes. The nucleation during the recrystallization 
begins in the shear bands due to the high deformation energy accumulated [27]. The nucleation occurred in the shear bands at the beginning of recrystallization and the new grains grew along the shear band direction, which was at approximately $35^{\circ}$ angle to the rolling direction. Most of the grains nucleated on the shear bands had a texture dominated by the $\eta$ fiber [11,27]. The strong $\gamma$ and $\lambda$ textures in the warm-rolled $0 \mathrm{Cu}$ sheet resulted in the nucleation of $\gamma$ and $\lambda$ oriented grains along the boundaries of deformed grains [11,12], but the low intensity of the shear band in this sample resulted in the lack of the nucleation sites for $\eta$ oriented grains [28] at the beginning of recrystallization. On the other hand, the high-density of the shear bands in warm-rolled $0.5 \mathrm{Cu}$ sample provided plenty of nucleation sites for the $\eta$ oriented grains, and resulted in the formation of a $\eta$ fiber dominated texture at the beginning of recrystallization.

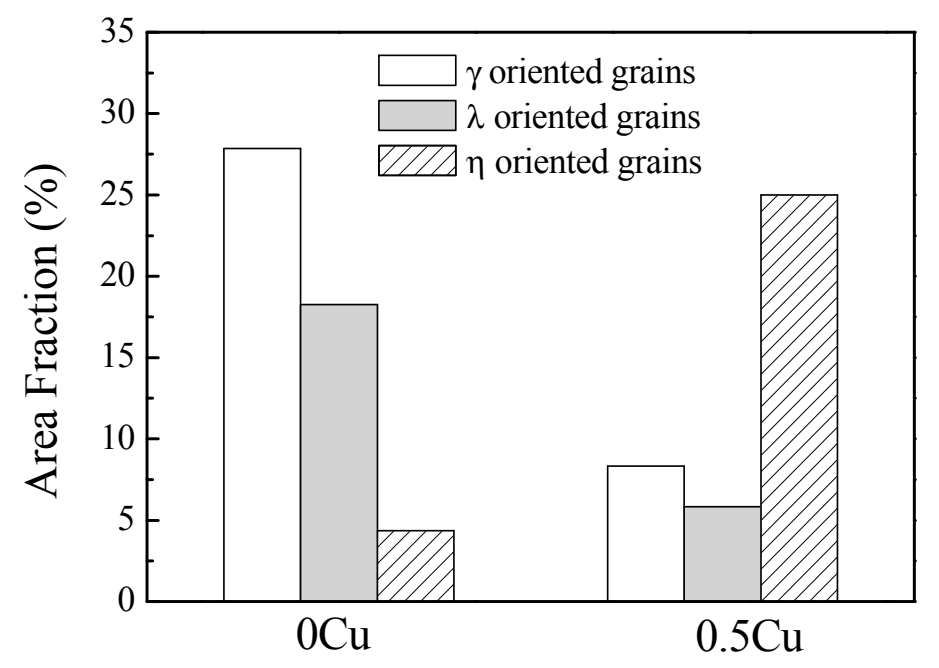

Figure 6. Proportion of $\gamma, \eta$ and $\lambda$ oriented grains in all recrystallized grains after annealing at $900{ }^{\circ} \mathrm{C}$ for $30 \mathrm{~s}$ (deviation angle: $15^{\circ}$ ).

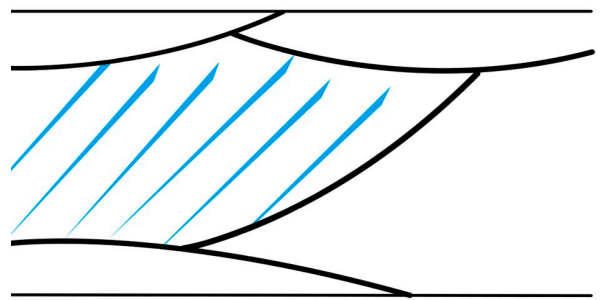

(a)

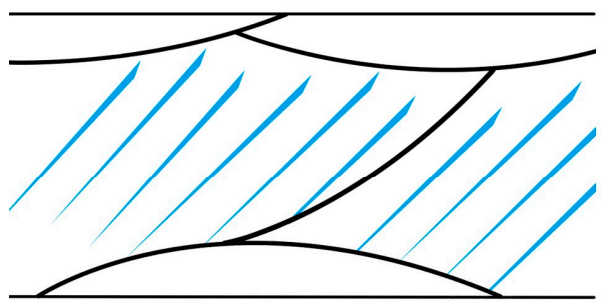

(c)

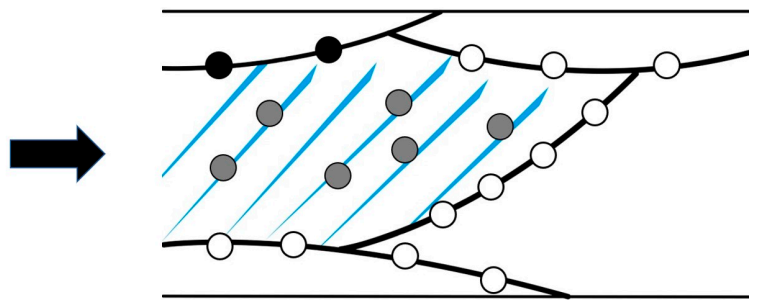

(b)

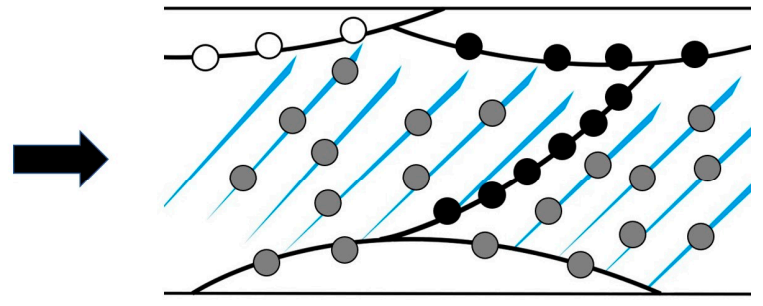

(d)

\rceil grains $\bigcirc \quad \gamma$ grains $\bigcirc$ other grains

Figure 7. The schematic diagram showing the recrystallization nucleation of the warm-rolled sheets during annealing treatment: shear bands in: $0 \mathrm{Cu}(\mathrm{a})$; and $0.5 \mathrm{Cu}(\mathrm{c})$ warm-rolled sheets; and the recrystallization nucleation of: 0Cu sample $(\mathbf{b})$; and $0.5 \mathrm{Cu}$ sample $(\mathbf{d})$. 
The grain orientations at the beginning of recrystallization have significant influence on the final recrystallization texture. In the $0 \mathrm{Cu}$ sample, large numbers of $\gamma$ and $\lambda$ oriented grains (nucleated at $\gamma$ and $\lambda$ deformed grains, respectively) were present at the beginning of recrystallization. However, the growth rate of $\gamma$ oriented grains was higher than that of the $\lambda$ oriented grains because the stored energy in the $\gamma$ deformed grains is higher than in the $\lambda$ deformed grains $[29,30]$. Thus, the $\gamma$ texture dominated the recrystallization microstructure of the $0 \mathrm{Cu}$ sample after annealing. For the $0.5 \mathrm{Cu}$ sample, the $\eta$ oriented grains (including Goss oriented grains) nucleated at shear bands in $\{111\}<112>$ deformed matrices at the beginning of recrystallization. $\Sigma 19$ grain boundaries with high migration rate can form between the nucleated Goss oriented grains and the deformed matrices, which can favor the growth of Goss oriented grains [31-33]. Moreover, the dominant texture in the surface of the warm-rolled $0.5 \mathrm{Cu}$ sample was Goss texture. These warm-rolled textures will remain and grow in subsequent annealing processes, which will enhance the $\eta$ fiber (especially Goss) after annealing and lead to $\eta$ recrystallization texture with a peak at Goss with improved magnetic properties.

\section{Conclusions}

(1) The addition of $0.5 \mathrm{wt}$. \% Cu promoted the formation of shear bands after warm rolling, and strengthened the $\{110\}<001>$ texture at surface layer and $\{111\}<112>$ texture in the middle layer.

(2) The shear bands in $\{111\}<112>$ oriented grains acted as the nucleation sites of $\eta$ oriented grains and hence promoted the growth of Goss oriented grains.

(3) After recrystallization, the dominant texture in the $0.5 \mathrm{Cu}$ sample consisted of mainly $\eta$ fiber with a peak at Goss, while the texture of the $0 \mathrm{Cu}$ sample was characterized by a combination of $\gamma, \eta$ and $\lambda$ fibers.

(4) The $0.5 \mathrm{Cu}$ sample had higher magnetic induction than the $0 \mathrm{Cu}$ sample due to the formation of relatively stronger $\eta$ fiber texture through the thickness.

Acknowledgments: This work is supported by the Science and Technology Project of Hubei (2016AAA026), and the Postdoctoral Science Foundation of China (2016M602375).

Author Contributions: Jing Liu, Zhaoyang Cheng and Jiachen Zhu conceived and designed the experiments; Zhaoyang Cheng and Jiachen Zhu performed the experiments; Jing Liu, Zhaoyang Cheng, Jiachen Zhu and Zhidong Xiang analyzed the data; Juan Jia contributed analysis tools; Zhaoyang Cheng wrote the paper. Zhidong Xiang and Yunjie Bi participated the revision of the manuscript. All authors had commented on the manuscript.

Conflicts of Interest: The authors declare no conflict of interest.

\section{References}

1. Li, H.; Liang, Y.F.; Ye, F. Evolution of Microstructure and Ordering in Rolling Process of Fe-6.5 mass\% Si Alloy. J. Iron Steel Res. Int. 2016, 23, 453-458. [CrossRef]

2. Fan, X.A.; Wu, Z.Y.; Li, G.Q.; Xiang, Z.D.; Gan, Z.H. High resistivity and low core loss of intergranular insulated $\mathrm{Fe}-6.5 \mathrm{wt} \% \mathrm{Si} / \mathrm{SiO}_{2}$, composite compacts. Mater. Des. 2016, 89, 1251-1258. [CrossRef]

3. Bolfarini, C.; Silva, M.C.A.; Jorge, A.M., Jr.; Kiminami, C.S.; Botta, W.J. Magnetic properties of spray-formed $\mathrm{Fe}-6.5 \% \mathrm{Si}$ and $\mathrm{Fe}-6.5 \% \mathrm{Si}-1.0 \% \mathrm{Al}$ after rolling and heat treatment. J. Magn. Magn. Mater. 2008, 320, e653-e656. [CrossRef]

4. Wu, Z.Y.; Fan, X.A.; Li, G.Q.; Gan, Z.H. Intergranular insulated Fe-6.5 wt \% Si $/ \mathrm{SiO}_{2}$ composite compacts with tunable insulating layer thickness for low core loss applications. RSC Adv. 2015, 5, 67031-67040. [CrossRef]

5. Qin, J.; Yang, P.; Mao, W.M.; Ye, F. Punchability and Punching Fracture Behavior of High Silicon Steel Sheets. J. Iron Steel Res. Int. 2015, 22, 852-857. [CrossRef]

6. Takada, Y.; Abe, M.; Masuda, S.; Inagaki, J. Commercial scale production of Fe- 6.5 wt \% Si sheet and its magnetic properties. J. Appl. Phys. 1988, 64, 5367-5369. [CrossRef]

7. Haiji, H.; Okada, K.; Hiratani, T.; Abe, M.; Ninomiya, M. Magnetic properties and workability of $6.5 \% \mathrm{Si}$ steel sheet. J. Magn. Magn. Mater. 1996, 160, 109-114. [CrossRef] 
8. Wu, J.; Zhang, L.; Gong, T.; Zhu, J.; Hao, Q.L.; Qin, Z.; Cong, S.H.; Zhan, D.F.; Xiang, Z.D. Texture evolution of the surface layer of high silicon gradient electrical steel and influence on the magnetic properties. Vacuum 2015, 119, 189-195. [CrossRef]

9. Ros-Yañez, T.; Houbaert, Y.; Fischer, O.; Schneider, J. Production of high silicon steel for electrical applications by thermomechanical processing. J. Mater. Process Technol. 2003, 143, 916-921. [CrossRef]

10. Quadir, M.Z.; Duggan, B.J. A microstructural study of the origins of $\gamma$ recrystallization textures in $75 \%$ warm rolled IF steel. Acta Mater. 2006, 54, 4337-4350. [CrossRef]

11. Barnett, M.R. Role of In-grain Shear Bands in the Nucleation of $<111>/$ /ND Recrystallization Textures in Warm Rolled Steel. ISIJ Int. 1998, 38, 78-85. [CrossRef]

12. Takashima, M.; Komatsubara, M.; Morito, N. $\{001\}<210>$ Texture Development by Two-stage Cold Rolling Method in Non-oriented Electrical Steel. ISIJ Int. 1997, 37, 1263-1268. [CrossRef]

13. Liu, J.L.; Sha, Y.H.; Zhang, F.; Li, J.C.; Yao, Y.C.; Zuo, L. Development of $\{210\}<001>$ recrystallization texture in Fe-6.5 wt. \% Si thin sheets. Scr. Mater. 2011, 65, 292-295. [CrossRef]

14. Fang, X.S.; Liang, Y.F.; Ye, F.; Lin, J.P. Cold rolled Fe-6.5 wt \% Si alloy foils with high magnetic induction. J. Appl. Phys. 2012, 111, 094913. [CrossRef]

15. Yao, Y.C.; Sha, Y.H.; Liu, J.L.; Zhang, F.; Zuo, L. Texture and Magnetic Properties of Rolled Fe-6.5 wt. \% Si Thin Sheets. J. Electron. Mater. 2014, 43, 121-125. [CrossRef]

16. Cheng, Z.Y.; Liu, J.; Chen, W.S.; Zhu, J.C.; Lin, X.F.; Xiang, Z.D. Effect of 0.5 mass\% Cu Addition on Ductility and Magnetic Properties of Fe-6.5Si Alloy. J. Iron Steel Res. Int. 2016, 23, 717-721. [CrossRef]

17. Bian, X.H.; Zeng, Y.P.; Nan, D.; Wu, M. The effect of copper precipitates on the recrystallization textures and magnetic properties of non-oriented electrical steels. J. Alloys Compd. 2014, 588, 108-113. [CrossRef]

18. Toroghinejad, M.R.; Ashrafizadeh, F.; Najafizadeh, A.; Humphreys, A.O.; Liu, D.; Jonas, J.J. Effect of rolling temperature on the deformation and recrystallization textures of warm-rolled steels. Metall. Mater. Trans. A 2003, 34, 1163-1174. [CrossRef]

19. Rusakov, G.M.; Redikul'Tsev, A.A.; Kagan, I.V.; Lobanov, M.L. Mechanism of formation of shear bands upon cold deformation of a commercial Fe-3\% Si alloy. Phys. Met. Metallogr. 2010, 109, 662-669. [CrossRef]

20. Murakami, K.; Morishige, N.; Ushioda, K. The Effect of Cold Rolling Reduction on Shear Band and Texture Formation in Fe-3\%Si Alloy. Mater. Sci. Forum 2012, 715-716, 158-163. [CrossRef]

21. Humphreys, A.O.; Liu, D.; Toroghinejad, M.R.; Essadiqi, Q.; Jonas, J.J. Warm rolling behaviour of low carbon steels. Mater. Sci. Technol. 2013, 19, 709-714. [CrossRef]

22. Liu, H.T.; Liu, Z.Y.; Sun, Y.; Gao, F.; Wang, G.D. Development of $\lambda$-fiber recrystallization texture and magnetic property in Fe-6.5 wt \% Si thin sheet produced by strip casting and warm rolling method. Mater. Lett. 2013, 91, 150-153. [CrossRef]

23. Qin, J.; Yang, P.; Mao, W.M.; Ye, F. Effect of texture and grain size on the magnetic flux density and core loss of cold-rolled high silicon steel sheets. J. Magn. Magn. Mater. 2015, 393, 537-543. [CrossRef]

24. Calvillo, N.; Soria, M.J.; Salinas, A.; Gutiérrez, E.J.; Reyes, I.A.; Carrillo, F.R. Influence of thickness and chemical composition of hot-rolled bands on the final microstructure and magnetic properties of non-oriented electrical steel sheets subjected to two different decarburizing atmospheres. Metals 2017, 7, 229. [CrossRef]

25. Pan, H.J.; Zhang, Z.H.; Mo, Y.K.; Xie, J.X. Strong <001> recrystallization texture component in 6.5 wt \% Si electrical steel thin sheets by secondary cold rolling and annealing. J. Magn. Magn. Mater. 2016, 419, 500-511. [CrossRef]

26. Nguyen-Minh, T.; Sidor, J.J.; Petrov, R.H.; Kestens, L.A.I. Occurrence of shear bands in rotated Goss $(\{110\}<110>)$ orientations of metals with bcc crystal structure. Scr. Mater. 2012, 67, 935-938. [CrossRef]

27. Paolinelli, S.D.C.; Cunha, M.A.D.; Cota, A.B. The influence of shear bands on final structure and magnetic properties of 3\% Si non-oriented silicon steel. J. Magn. Magn. Mater. 2008, 320, e641-e644. [CrossRef]

28. Yao, Y.C.; Sha, Y.H.; Liu, J.L.; Zhang, F.; Zuo, L. Texture and Microstructure for Magnetic Properties of Two-Stage Cold-Rolled Fe-6.5 Wt Pct Si Thin Sheets. Metall. Mater. Trans. A 2015, 47, 5771-5776. [CrossRef]

29. Barnett, M.R.; Jonas, J.J. Influence of ferrite rolling temperature on microstructure and texture in deformed low C and IF steels. ISIJ Int. 1997, 37, 697-705. [CrossRef]

30. Kestens, L.; Jonas, J.J. Modelling texture change during the static recrystallization of a cold rolled and annealed ultra-low carbon steel previously warm rolled in the ferrite region. ISIJ Int. 1997, 37, 807-814. [CrossRef] 
31. Lin, P.; Palumbo, G.; Harase, J.; Aust, K.T. Coincidence site lattice (CSL) grain boundaries and Goss texture development in Fe-3\% Si alloy. Acta Mater. 1996, 44, 4677-4683. [CrossRef]

32. Sha, Y.H.; Sun, C.; Zhang, F.; Petal, D.; Chen, X.; Kalidindi, S.R.; Zuo, L. Strong cube recrystallization texture in silicon steel by twin-roll casting process. Acta Mater. 2014, 76, 106-117. [CrossRef]

33. Park, J.T.; Szpunar, J.A. Evolution of recrystallization texture in non-oriented electrical steels. Acta Mater. 2003, 51, 3037-3051. [CrossRef]

(C) 2018 by the authors. Licensee MDPI, Basel, Switzerland. This article is an open access article distributed under the terms and conditions of the Creative Commons Attribution (CC BY) license (http://creativecommons.org/licenses/by/4.0/). 